\title{
As razões do coração
}

\author{
ERASMO GARCIA MENDES
}

$\mathrm{P}$

OR QUE TERIA o coração razões que a própria razão desconhece? Blaise Pascal (1632-1662), que formulou essa conhecida sentença, foi filósofo na acepção que antigamente se dava ao vocábulo, isto é, além de filósofo era cientista (precoce). Aos 11 anos estudou as leis da acústica; aos 16, redescobriu a $32^{a}$ proposição de Euclides; ainda aos 16 escreveu um ensaio sobre o ramo da geometria que trata das seções cônicas, que surpreendeu, entre outros, Descartes; aos 19, inventou uma máquina de somar (até hoje conservada no Musée Ranquet, em Clermont-Ferrand, sua terra natal); subseqüentemente desenvolveu a idéia da prensa hidráulica, formulou o princípio da hidrostática (1653) e antecipou a teoria da probabilidade.

Mas como, de acordo com Ortega y Gasset, somos nós e a nossa circunstância, Pascal em matéria biológica viveu sua época. Assim como Descartes (15961654), no mesmo século, sem razão plausível, sediou, em De Homine, a alma na glândula pineal, Pascal teria aceito a crença de que o coração, um músculo, pudesse ter, além de sentimentos, razões. E, até hoje, perdura essa idéia de que o órgão, uma estrutura apenas inervada, mas não nervosa, possa gerar sensações. No dicionário de Webster, entre as acepções da palavra coração está a de que é a sede das emoções, da personalidade, do lado moral da natureza do homem. Seria provável, porém, que Pascal, mente arguta, até se tivesse dado conta da impossibilidade de ter o coração razões e usado o órgão metaforicamente. Nesse sentido, teria se antecipado, cerca de três séculos, a João Cabral de Mello Neto que, em "España en el Corazón", também usou o órgão como metáfora, opondo-o, nessa condição, ao órgão funcionalmente encarado (fez o mesmo com outra "tripa", o colhão) para falar da Espanha "enquanto entidade não sentimental, mas visceral” (J. Uchoa Leite em "João Cabral de Mello Neto e a Tripa”, FSP, Mais, 17.10.1999).

Caberia, no entanto, indagar como, no passado, foi se formando a concepção do coração como órgão sensorial e racional. A história remonta à antigüidade clássica. Aristóteles admitiu que o coração era fonte de sensações pois se, como acreditava, era fonte de calor, aí estaria também a origem das sensações (dor, prazer, desejo e outras reações emocionais), daí a palpitação que aparece nas comoções. Ignorou os nervos, as artérias levariam as mensagens, os movimentos do corpo seriam produzido por retração e afrouxamento do coração. Atribuiu, assim, a esse órgão uma função nervosa. Já Galeno (130 DC) admitiu o coração entre os três órgãos que governam a atividade do corpo, mas não teria se interessado em explicar por que o coração teria razões e sentimentos. Essa crença varou séculos, até que os crescentes conhecimentos morfológicos (aí incluídos os histológicos) e 
fisiológicos mostrassem claramente que, sendo um músculo, o coração não poderia ter sentimentos e, muito menos, razões. De fato, esse músculo mostrou-se somente capaz de se contrair e relaxar espontânea e ritmicamente (miogenicidade). Os nervos que o suprem têm uma função apenas cardiorreguladora, adequando, por exemplo, a freqüência dos batimentos às necessidades fisiológicas.

Essa inervação do coração é feita pelo sistema nervoso autônomo (SNA), cujas fibras fazem parte de dois tipos de neurônios que se sinaptam (contatam) num gânglio; as fibras (axônios) dos pós-ganglionares inervam os órgãos. No caso do coração, as fibras pós-ganglionares da divisão (orto) simpática do SNA liberam nor-adrenalina, que aumenta a freqüência cardíaca; as da divisão parassimpática (vagais) liberam acetilcolina, que diminui essa freqüência.

O coração está sujeito, é importante notar, à nor-adrenalina (e adrenalina) de descarga das glândulas suprarrenais, cuja medula é, filogeneticamente, uma região ganglionar, pois recebe fibras pré-ganglionares regulares. Numa situação de emergência - (atenção ou emoção diante de um evento, preparação para perseguição ou fuga) - essas glândulas liberam grandes quantidades de, digamos para simplificar, adrenalina, dando azo à expressão já popular "pura adrenalina" para designar um episódio sensacional que nos deixa em suspense. Essa adrenalina liberada é um importante componente da chamada "Reação de Alarme" (W. Cannon), que predispõe o organismo a enfrentar uma situação adversa; aumenta, p. ex., os batimentos cardíacos e, conseqüentemente, melhora a circulação para os músculos encarregados da resposta motora a essa situação.

Compreende-se, assim, que numa violenta emoção possa ocorrer grande liberação de adrenalina, com possíveis efeitos danosos para o coração. Por seu turno, os neurônios pós-ganglionares da divisão parassimpática do SNA, quando estimulados excessivamente, liberam grandes quantidades de acetilcolina, que, por sua ação inibidora sobre os batimentos cardíacos, pode ter efeitos igualmente danosos.

Ora, por que emoções (não apenas reação psíquica a eventos, mas a simples evocações) ou a necessidade de um estado de alerta repercutem na atividade do SNA? É que os corpos celulares dos neurônios pré-ganglionares se situam no sistema nervoso central (SNC) e aí estabelecem conexões com importantes centros encefálicos no chamado sistema límbico, cujos componentes formam um complexo interligado, que inclui importantíssimos núcleos (como o hipocampo e a amígdala) e em meio do qual se situa o hipotálamo. Esses núcleos conectam-se com o córtex cerebral e, neste, nenhuma sensação gerada se sustenta ou adquire significado se a informação causadora não chegar simultaneamente a tais núcleos. Assim, o sistema límbico é como um computador que processa a informação sensorial, integra-a e dá-lhe colorido emocional. O hipotálamo é o seu elo com o SNA. As fibras préganglionares do sistema parassimpático pertencem ao X par de nervos cranianos (vago ou pneumogástrico) e se sinaptam com as pós-ganglionares (curtas) nas imediações dos próprios órgãos que inervam. 
Esses conhecimentos da anatomia e da fisiologia do coração humano são hoje de domínio de qualquer estudante que tenha passado por um eficiente curso universitário básico de disciplinas biológicas. Na verdade, já repercutem em campos científicos não-biológicos, não raro invadindo até setores literários. Veja-se, a propósito, o caso do poeta Paul Valéry. Numa carta enviada a um professor da Universidade de Montpellier, a propósito de sua obra $A$ alma e a dança, o grande poeta francês ressaltou como o conhecimento das atividades de nervos simpáticos e parassimpáticos (pneumogástrico ou vago) havia modificado a concepção dos sentimentos e emoções de manifestações do espírito em meros escravos do sistema vegetativo.

Mas são certamente escassos os ficcionistas e poetas que aceitaram passivamente o condicionamento pelo sistema autônomo dos vários tipos de sentimentos e emoções. Os que aceitaram essa sujeição, como Valéry (matemático de origem), tiveram de algum modo ligações com a ciência, como Aldous Huxley, por exemplo, em Contraponto ou As portas da percepção, que refletem o fato de ser o autor descendente do grande T. H. Huxley e contemporâneo de dois outros Huxley (Julian e Andrew), importantes biólogos da atualidade.

Mas, via de regra, a queixa tem sido a de estarem os avanços da ciência crescentemente despojando a criação literária (sobretudo a poética) de sua sedução, de seu encanto e de suas motivações estéticas. Assim, John Keats (1795-1821) acusou Isaac Newton (1642-1727) de ter destruído a beleza do arco-íris, reduzindo-o a meras cores prismáticas. No mesmo século, Edgar Allan Poe (18091849) foi bem mais acerbo no soneto To Science, abaixo transcrito em tradução estritamente ao pé da letra:

Ciência! a vera filha do Velho tempo tu és,

Que alteras todas as cousas com teus olhos perscrutantes.

Por que predas assim no coração do poeta, oh

Abutre, cujas asas são baças realidades?

Como poderia ele te amar, ou, julgar-te sábia

Quando não o deixas na sua peregrinação

Na busca do tesouro nos céus plenos de jóias,

Ainda que te alteies com asa intrépida?

Não arrastaste Diana fora de seu carro?

E removeste a Hamadríade fora do bosque

Para procurar abrigo em algum astro mais feliz?

Não forçaste a Náiade para fora de seu lago,

O elfo da verde relva, a mim próprio

Do sonho estival sob o tamarindo? 
Esse apregoado antagonismo entre as atividades literária e científica esteve provavelmente na mente de C. P. Snow, quando, em 1959, escreveu The two cultures and the Scientific Revolution. Nesse livro, Snow afirmou que a ciência representa o futuro e a literatura a tradição cega e surda às repercussões dos avanços científicos. Os que se empenhavam em outras atividades culturais não-científicas além da literatura seriam, como esta, obstáculos à evolução humana. Não obstante Snow, cientista, se pretendia também romancista, contrariando a sua tese de duas inconciliáveis culturas, a científica e a literária. Seu livro, como esperado, suscitou intensa polêmica que se estende até hoje, tendo sido abordada mais recentemente por Vargas Llosa (FSP, Mais, 23.1.1993); envolveu intelectuais do porte de Isaiah Berlin e críticos literários famosos, como o inglês F. R. Lewis.

No seu livro Two cultures? The significance of C. P. Snow (1963), Lewis, tão sectariamente quanto Snow no seu, procurou atingir este em termos algo violentos. Insurgiu-se contra a concepção de Snow sobre a existência de duas inconciliáveis culturas, a científica e a literária. Essa concepção contrariaria a própria noção de cultura, que não implica apenas a aquisição de conhecimentos, mas também o enriquecimento da mente. Assim, ler Dickens, ouvir Mozart, ver um Tiziano são atividades culturais essencialmente tão importantes quanto estar ao corrente dos avanços científicos. Lewis não era obviamente contra a tecnologia resultante das ciências, mas partilhava da opinião de que a freqüência aos cursos superiores, sobretudo aos que levavam às ciências ou a certas profissionalizações, deveria começar sempre por disciplinas de cunho humanístico como estudos históricos, sociais e, sobretudo, fundamentos da filosofia. Temia que a universidade estivesse se tornando cada vez mais científica, a ponto de não mais justificar, na pós-graduação, o título de doutor em filosofia (PhD), mas apenas o de doutor em algum curso universitário. Pois, a rigor, ninguém poderá pretender ser $\mathrm{PhD}$ se não tiver se doutorado na própria filosofia ou em curso de doutorado em que a essência dessa disciplina seja ministrada, como nas velhas universidades alemãs e inglesas.

Presumiu-se anteriormente que Snow, ao elaborar a sua concepção de duas culturas, tivesse levado em conta o caso das razões que Pascal atribuiu ao coração. Pois, à vista dos conhecimentos atuais, as razões do filósofo poderiam ter sido usadas no combate que ele moveu contra o obscurantismo, cuja existência ele admitiu nas culturas não-científicas. De fato, Pascal poderia ter considerado manifestações do coração em resposta à estimulação nervosa, como evidências de uma capacidade do órgão de ter sentimentos e razões. A não ser que, como aventado inicialmente, tenha usado o coração metaforicamente.

O fato, porém, é que, até hoje, tem sido vulgarmente admitido que "sofre" com as circunstâncias adversas e "enche-se de alegria" com os eventos prazerosos, dando azo a que seja usado na ficção literária tanto quanto nas letras das canções populares e, mesmo, clássicas. Adjetivos como cordial, cordato etc., continuam a 
indicar ser a pessoa amável ou de acordo (outro derivado!) com algo sugerido ou proposto.

Haveria algum mal na tradicional aceitação do coração como órgão dotado de sentimentos e até razões? De modo algum. O homem é o único animal capaz de pensar racional e/ou fantasiosamente, o que lhe faculta analisar criticamente ou crer piamente nos mitos que lhe são incutidos desde a infância ou decorrentes da tradição das comunidades em que vivem. Continua, assim, como adulto, a crer ou fingir que crê, porque lhe apraz (ou o atemoriza) o relato de lendas e histórias que desafiam a lógica comum. O caso das razões do coração encaixar-se-ia no rol dos mitos gerados em eras remotas e persistentes no seio de uma comunidade.

Nesse sentido, são as comunidades selvagens que, pela sua estrutura aparentemente menos complexa, prestam-se melhor aos estudos das origens e dos significados dos mitos. Daí a importância das investigações dos antropólogos, como Lévi Strauss (por exemplo, em A oleira ciumenta), com nossos índios. Os resultados desses trabalhos servem à sociologia, à psicologia social e, mesmo, à psicanálise (veja-se o Totem e tabu, de Freud) e ajudam a entender os vários tipos de comportamentos em termos de tendências inatas ou adquiridas na vida comunitária. Seriam a crença e o encantamento com relatos fantásticos uma tendência inata surgida e mantida por seleção natural pelo seu valor de sobrevivência? Boring, psicólogo de Harvard, acentuou que a ilusão é o grande fator de sobrevivência. Se assim for, entende-se que, mesmo em adultos incréus de comunidades civilizadas perdure o gosto pelos contos fantásticos. Assim, quem não se sensibilizaria com o conto de Oscar Wilde, em que um homem ia à floresta para pegar lenha e, na volta, inventava histórias de ter visto silvanos dançando numa clareira; uma vez, viu-os realmente e, nesse dia, no retorno à aldeia, não teve história para contar. Quem, crente ou cético, não se impressionaria com o livro The turn of the screw de Henry James (no cinema, Os inocentes), em que duas crianças vêem cenas amorosas entre dois serviçais já falecidos?

O aproveitamento da obra de Henry James num filme de grande sucesso diz bem do interesse de produtores e diretores de cinema por temas que agradam ou atemorizam os crédulos em fantasias e, mesmo, aqueles que céticos ou descrentes conseguem ver nessas fantasias o lado simbólico, poético ou estético. Assim capacitam-se para gostar desde os mais ingênuos contos de fadas até filmes tenebrosos como Drácula e Frankenstein. A televisão não tardou em seguir essa trilha, tão valiosa como atrativo de audiência, enxertando ou tornando foco principal das novelas personagens e fatos fantásticos. Diante da tendência de fruir coisas míticas, quem poderia, pois, censurar os que crêem nas razões do coração, tomando conseqüências da estimulação nervosa (palpitações, arritmias, variação na freqüência de batimentos), como manifestações de júbilo ou tristeza do próprio órgão? 
Há, contudo, os que se aproveitam do fascínio pelas coisas míticas escrevendo farsas que alcançam grande sucesso. Um caso notável, reminiscente da era vitoriana, foi a farsa perpetrada por Jones, integrante do grupo humorista inglês Mount Python. Jones inspirou-se numa fotomontagem de uma menina cercada de fadas, publicada no jornal The Regular, em 1907. O alvoroço em torno da foto foi tão grande que até Conan Doyle acreditou que a menina Angelica Cottington tinha visto e prensado num livro fadas que a rodeavam, tal como descrito em Pressed fairy book, diário de Angelica, engenhosamente ideado por Jones.

Diante de tantos e fascinantes relatos míticos, críveis ou sujeitos à fria análise dos céticos, o melhor talvez seja seguir o conselho conciliador de Fernando Pessoa que, evocando um grande mito português, disse, em Ode à Liberdade, "quanto é bom, quando há bruma, esperar por D. Sebastião, quer venha ou não". Se não houver exagero ou morbidez na aceitação dos mitos, eles servirão para atenuar as agruras de um cotidiano não raro duro de suportar.

Erasmo Garcia Mendes, integrante do Conselho e da Mesa Editorial de ESTUDOS AVANCADOS, foi professor-titular aposentado de Fisiologia e professor emérito do Instituto de Biociências da Universidade de São Paulo.

Agradeceu a suas colegas professoras Eudoxia Froehlich, pelo empréstimo do livro Pressed fairy book e Marilene S.C. Bianconcini pela leitura crítica do texto.

O autor faleceu no dia 19 de fevereiro passado. Era sua intenção encaminhar este texto para publicação na revista. 